\title{
EVERYWHERE AND NOWHERE: NEARSHORE SOFTWARE DEVELOPMENT IN THE CONTEXT OF GLOBALISATION
}

\author{
Pamela Abbott \\ University College Dublin \\ Belfield \\ Dublin 4, IRELAND \\ Phone: +35317164735 \\ Fax: +35317164783 \\ E-mail: pamela.abbott@ucd.ie
}

\author{
Matthew Jones \\ University of Cambridge \\ Trumpington $\mathrm{St}$ \\ Cambridge CB2 1AG, UK \\ Phone: +44 1223339606 \\ Fax: +44 1223339701 \\ E-mail: mrj10@cam.ac.uk
}

\begin{abstract}
Offshore software outsourcing, a major contributor to globally distributed work (GDW), has been identified as one of the most striking manifestations of contemporary globalisation. In particular, offshoring resonates with influential views that suggest that ICTs have rendered location irrelevant. Some research, however, has questioned this "placeless logic" and suggested that location may be significant to the success of offshoring ventures. In this paper, we draw on evidence from two nearshore software development ventures in the Caribbean to identify a number of locational characteristics relating to the physical, economic and cultural setting, local resources and government policy that may be important in influencing the suitability of offshore outsourcing venues. Some of these are recognised, even by companies pursuing placeless location strategies, while others were unanticipated. The cases also suggest that companies may be able to actively shape certain characteristics to their advantage. Implications for vendors and clients of nearshore information services, and potentially also for companies considering offshore ventures in non-traditional locations, are identified.
\end{abstract}

Keywords: globalisation, offshore outsourcing, nearshore outsourcing, software development, developing countries

\section{Introduction}

By definition, IT offshoring, a major contributor to the phenomenon of globally distributed work (GDW), involves client and vendor companies that are located in different countries. This is seen to have negative effects on client/vendor interaction as geographical separation may possibly give rise to communication and control problems (Carmel et al. 2001; Sarker et al. 2004). This issue has been brought to the fore by the emergence of India, and latterly China, as major offshoring centres, both of which are located at a considerable distance from North America and Western Europe where most offshoring clients are based.

One result of these concerns has been the emergence of so-called proximity, or nearshore, development centres in locations closer to the client (Abbott et al. 2002; Carmel et al. Forthcoming) that are presumed to experience fewer problems of geographical separation. Such centres have been established both by new entrants seeking a software development 
presence near to the USA or Western Europe that have not traditionally been a source of IS services, such as North Africa, the Caribbean or the Baltic States (Economist 2005; King 1999; Tran 2004), and by incumbent offshore companies, primarily from India, providing their own nearshore hubs (Express 2004; Satyam 2004).

Although an array of countries have been identified in the practitioner literature as potential venues for nearshore work (Radkevitch 2005; Tran 2004; Carmel et al. Forthcoming), lack of significant experience in this area means that vendor companies face difficulties in deciding where to locate such ventures and clients have little guidance on how to assess their relative viability. A key question facing both vendors and clients is thus, "what characteristics, if any, of a location make it an effective site for nearshore development?"

The qualifier "if any" exists since a pervasive opinion in the literature on offshoring and on contemporary economic development is that information services are not tied to any particular location. Thus, Cairncross (1997, p. xi) states, "[c]ompanies will locate any screen-based activity anywhere on earth, wherever they can find the best bargain of skills and productivity", and Heeks (1999) argues, "[in developing countries] Computer Science graduates need arm themselves with just a PC and a couple of user contacts... and they are global 'info-preneurs"'. Technical skills and minimal infrastructure, therefore, are all that are seen to be needed for a viable offshoring solution.

The location of work is seen to be similarly irrelevant for groups involved in globally distributed information services. For example, the term "location transparency" is used by Carmel (1999, p 13) to describe how technology is "eliminating the perception of distance" in global software teams. A comparable view may apply to whole organisations. For example, Infosys, a leading Indian offshore software company, offers a "Global Delivery Model"1, drawing on its network of geographically-distributed development sites to provide a seamless production process, irrespective of where work is actually done. These views appear to resonate with influential theories of globalisation that suggest that information and communication technologies (ICTs) have all but eliminated spatial constraints on economic activity (Ohmae 1990; Quah 1998).

Other research suggests, however, that characteristics of a location may be significant to the success of offshoring ventures. Some studies have, for example, attempted to classify locations in terms of their feasibility for offering competitive information services, addressing characteristics such as human capital factors, infrastructure, government policy, and linkages to the international community (Carmel 2003; Heeks et al. 2004) while others have provided client-focused, country-level analyses of location risk, based on such concerns as geopolitical stability and cultural similarity (Minevich et al. 2005; Rao 2004). Other studies have sought to identify the characteristics of existing offshore locations, especially India, that may account for their success (Krishna et al. 2000; Zatolyuk et al. 2004). This work is supported by research in geography and sociology that emphasises continuing diversity within globalisation (Appadurai 1996; Robertson 1992) and the enduring significance of location (Cox 1997b; Goddard et al. 1996).

While these debates on the significance of location form an important context for decisions on potential nearshore development sites, they would seem insufficient to inform either vendors or clients on the suitability of specific locations. Thus "location transparency"-type

\footnotetext{
${ }^{1}$ http://www.infosys.com/gdm/default.asp
} 
arguments suggest that any site should be as good as any other, while the claims that location still matters are either made for whole countries (implying that $a$ specific location is unimportant and that vendors can do nothing to improve the attractiveness of a location), or draw on data from established offshoring locations that may not apply in non-traditional and/or nearshore settings.

In this paper, therefore, we present case studies of two nearshore software development ventures in the Caribbean seen as illustrating different approaches to location. One adopted a strategy that appeared to reflect arguments for the irrelevance of location, while the other's strategy sought to promote features of its setting to its advantage. While the two cases cannot provide definitive insight on the importance, or otherwise, of location, they significantly add to the sparse literature on nearshore development by providing in-depth evidence on specific ventures and connecting this with wider debates on contemporary economic development and its spatial organisation. Given the increasing interest in finding new locations for offshore development, spurred by rising costs in traditional centres (Edwards 2004), moreover, the issues identified from these nearshore cases may also be relevant to vendors and clients considering locating development centres in these new offshore settings. The findings may therefore help to improve our understanding of the significance of location in vendor/client relationships and site selection strategies for offshoring more generally.

Since offshoring in general, and the nearshore case studies in particular, may be seen as reflecting wider debates on the significance of location in the context of globalisation (Sahay et al. 2003, pp. 27-50), the following section presents an introduction to the relevant theoretical arguments, as these have not been widely discussed in the IS literature to date. Then, following an account of the research methodology, the two case studies are presented and discussed in terms of the evidence they offer on the significance of location and on the theoretical debates on globalisation. Implications for vendor and client companies considering locating offshore development ventures in non-traditional settings are identified.

\section{ICTs and the Location of Work in a Globalised World}

The view of modern information technologies enabling the "disembedding" (Giddens 1990) of social (or work) practices from particular geographical locations is not restricted to offshoring literature, but has been widely-discussed in geography, sociology and management. A central concept arising is the distinction between space and place, where space is defined as "physically bounded geographical areas in which social interactions take place with little meaning or intentionality ascribed", and place as "locales contextualised through the sharing of common symbols and experiences" (Giddens 1990; Sahay et al. 2003, pp. 112-131). Historically, space and place largely coincided, with activity taking place in contextualised locales (Giddens 1990) that were socially meaningful. For example, work took place in factories or offices where workers were co-located. With the development of modern communication technologies, however, the two can become increasingly separated, as meaningful interactions occur with others outside the immediate locale. For example, a British customer's contact centre may be located in India. Alternatively, meaningful aspects of a location may be reproduced in remote physical settings, creating for the business person, for example, the familiar milieu of the international hotel anywhere in the world. Either way, physical space becomes emptied of its significance, giving rise to the "placeless logic" driving global software work (Sahay et al. 2003, p. 35) and the location substitutability leading to irrelevance of local context in choosing work sites (Cox 1997a; Storper 1997). Offshoring is seen as one of the most striking manifestations of this process and as one of the 
modern world's great "flatteners", creating an economic "level playing field" between developing and developed nations (Friedman 2005)

Proponents of globalisation also identify knowledge and knowledge work, of which software development is key, as central to the emergence of the "borderless world" (Ohmae 1990). Cairncross (1997) talks of the "death of distance", as ICTs have transcended physical space and thereby increased the capacity for global interaction. The impacts of these developments are realised economically, with increased integration of markets and financial institutions, socially, with more cultural homogenisation and politically, with the "shrinking" of the nation-state. A related theme emerges from the work of Castells (1996) who emphasises that ICT-supported placeless connections (the space of flows), for example between financial centres, increasingly dominate the physical "space of places". Thus, power and wealth come not from location, but through connection to information networks. This may be significant in terms of the relationship between offshoring and economic development, since software "export enclaves" (Heeks 1999) may operate relatively independently of their physical location.

As compelling as this view of placeless work may be, its underlying assumptions may be questioned. It has been argued, for example, that although increased use of ICTs, especially in telemediated services, enables the use of new locations, this does not mean that differences between places no longer matter (Goddard et al. 1996). Instead, differentiation between locations can exist in terms of resources and can be employed to foster competitive advantage. For example, Israel's position as one of the world's leading software exporters has been attributed, in part, to its development of strong niche expertise stemming from local military technical training (Heeks et al. 2004). The more ICTs break down the physical barriers of space, therefore, the more particularities of "place" become important (Cox 1997a). This point is reinforced particularly well in (Sahay et al. 2003, pp. 112-131) where an example is given of globally distributed software teams using electronic collaborative spaces which, while eliminating the requirement for physically bounded space, increased in developers a need to attach place-like significance to their placeless collaborative spaces in order to structure their work.

\section{Methodology}

Although attracting increasing attention, the incidence of nearshore outsourcing is very limited, with only a few locations having any extended experience of such work. The topic has also received little discussion in the academic literature, either in Information Systems or Development Studies. An exploratory approach employing an interpretive case study method was therefore considered appropriate (Orlikowski et al. 1991; Walsham 1993) to gain insight on this emerging phenomenon.

Having identified two nearshore ventures in the Caribbean, primary data were gathered from site visits, published materials and semi-structured interviews with employees and outsourcing practitioners knowledgeable about the Caribbean context ${ }^{2}$. Interviews were conducted by telephone and face-to-face and typically lasted forty-five minutes. The interview protocol covered questions concerning the motivation for, development and sustaining features of the nearshore enterprise as well as how the interviewees interpreted and

\footnotetext{
${ }^{2}$ The names of the companies and individuals associated have been disguised and the published sources withheld so as to ensure confidentiality and anonymity.
} 
practiced the nearshore concept. Further data were gathered through structured email interviews with similar objectives. Online surveys were also undertaken on a wider basis to establish context and background for the study. Table 1 outlines the case study data sources used.

Table 1. Case study data sources

\begin{tabular}{|l|l|}
\hline Location of Firm & Data Sources \\
\hline Barbados, West Indies & $\begin{array}{l}8 \text { interviews (including 1 client), 1 site visit; } \\
\text { Documents related to the company, e.g. official news } \\
\text { reports, magazine articles, company report. }\end{array}$ \\
\hline Jamaica, West Indies & $\begin{array}{l}28 \text { interviews (including 1 client, government officials, } \\
\text { training institution officials); 1 site visit; documents } \\
\text { reviewed e.g. official reports, academic papers, company- } \\
\text { supplied promotional material, government documents }\end{array}$ \\
\hline
\end{tabular}

All interviews were transcribed and analysed using NUD*IST® to extract relevant themes. In the absence of any significant literature on nearshoring or the characteristics of location contributing to its effectiveness, a grounded analysis (Corbin et al. 1990) was adopted in which data were read and categorized into concepts suggested by the data rather than drawn from prior theory (Agar 1980). These concepts were then organized into recurring themes that appeared to provide stable and common categories linking several associated concepts.

\section{Case Descriptions}

\section{1. $\quad$ Nearshore Outsourcing in Barbados}

ZCO (Barbados) Ltd. (ZCOB), a software development centre, was a subsidiary of ZCO Group Inc., a USA-based information technology solutions integrator supplying IT services to US clients mainly from offshore resources in India. The unwillingness of ZCO's clients to travel to India and restrictions on the movement of labour to the USA encouraged the company to investigate bringing the outsourcing operation geographically closer. They wished to provide a place that had software talent like India but was not in India and which would be convenient for customers to travel to and do business. In 1994 the CEO of ZCO identified Barbados as a potential site for such an outsourcing venture. Contemporary reports described the concept:

"[ZCO's CEO] needed brainpower like India's, but he needed it to be in a better place... since the country he needed didn't exist, ... He would invent a place programmers would want to come to, a place they'd want to stay." (Inc Magazine 1998).

Among the factors influencing the decision to locate in Barbados were a liberal government policy on work permits, a favourable wage structure, a low tax rate, a modern telecommunications infrastructure, an English-speaking population, and convenient access to the USA (ZCO Annual Report, 1997). ZCOB's incorporation as an International Business Company (IBC) also made it eligible for certain government incentives such as exemption from import duties and repatriation of revenues earned. In return, ZCOB was expected to provide the impetus needed to jumpstart the Barbadian software industry by helping to 
provide new infrastructure, jobs for ancillary services, and encouragement for other IT investors (Inc Magazine 1998; Computer World 1999).

The attractiveness of Barbados as a tourist destination also played a role in creating a "programmer's paradise" as highlighted in press reports:

"The tennis part, of course, is abetted by the paradise part--an aspect of ZCO's invented location that attracts employees, customers, and investors alike. It is... a tropical island." (Inc Magazine 1998).

ZCO's targeted customers were Fortune 1000 companies in the financial services, banking and insurance sectors, a number of which supported the project with contributions to the value of \$12 million (Inc Magazine 1998).

Due to a shortage of sufficiently trained software engineers in Barbados, ZCOB recruited expatriates, who by 1999 comprised approximately two-thirds of the staff, most notably from India (Computer World 1999). One advantage for ZCO in relocating these employees was easier access to US work permits from Barbados, at a time when quotas from India were being capped (ZCOB Management Report 1999). ZCOB also sought to create a "worry-free, ready-built, turnkey life" (Inc Magazine 1998) for the expatriates by handling all their accommodation, transport and financial arrangements.

ZCOB at first proved to be very successful, growing rapidly to 350 staff, by 1998 . The company promoted its onshore/offshore/nearshore approach, as a significant contributor to its success (ZCO Annual Report 1997). Nearshore practitioners and customers familiar with the ZCO case attributed its allure to the proximity, similar time zones and other intangible aspects such as perceived cultural similarity that it shared with the USA:

"It's easier to visit either way - same day is good, just possible to do Barbados in 1 day. It makes a big difference in the psychological effect. London-Madras is a 12hour flight; there is a time-zone shift and culture [change]. Barbados is like the 51st state” (Nearshore Customer).

During 1998 and 1999, however, ZCOB's profits fell sharply and staff attrition became a problem, with numbers falling to 80 by June 1999. ZCOB's problems were attributed to excessively quick growth and, notably, the difficulty in selling Barbados as a destination for software development. One of the primary criticisms levelled at the company was its apparent failure to sell the nearshore concept, the very idea upon which it was predicated. The creation of a place like India seemed not to be convincing enough for it to be regarded in the same light as India:

"It was hard enough getting companies to send their programming work offshore, to places like India, but that alternative was at least well understood" (Inc Magazine 1999)

Interviews with nearshore practitioners, familiar with doing business in Barbados, and with $\mathrm{ZCO}$, confirmed the press reports. For example, it was felt that the cost of the operation was not necessarily cheaper than offshore solutions and therefore other angles should have been considered in order to make the choice of Barbados look more attractive than that of India. Physical proximity, alone, was apparently not enough. It was suggested, for example, that the type of work undertaken by the organisation had not been tailored so as to take advantage of the nearshore locations. 
"Production support is do-able due to the time zone advantage as opposed to India's time zone. Connectivity problems exist in India. Better to do this type of work in Barbados... For application areas in which the client is on unfamiliar grounds e.g. e-commerce, the near-shore model seems to be a better fit. " (Nearshore Practitioner 1).

Additionally, it was felt that the cost of the overseas recruitment (and retention) necessary to create this "programmers' paradise", should have been considered in the business model.

"[It is] difficult to retain Indian staff since most [of them] are intent on running away to the USA. There are not half of these problems with the Caribbean staff; recruitment would be easier." (Nearshore Practitioner 2).

There were also apparent problems with the choice of location. Although the island had all the necessary criteria to make it a viable offshore alternative, the idea of building something "like India" could not come to fruition, because of factors inherent to that site:

"Problems with setting up in Barbados - Too high cost; Small economy (tourism/sugar) - responsible for driving up costs; Property prices affected etc.;

... we should have chosen Trinidad/Jamaica; there would have been more business, more capital, more human resources and an Indian population [native to the island]" (Nearshore Practitioner 3).

The expected bonus to the local economy from ZCOB's success also seemed to be impaired by characteristics inherent to the community:

As an IBC, ZCOB was prevented from competing in the local market to protect local enterprises. As a result, they were unable to take advantage of local work, which led to underutilisation of staff when offshore contracts were in short supply. This also meant that, in practice, opportunities to transfer skills locally were very limited.

As an epilogue to this story, in the middle of 1999, ZCOB changed its name and management and continued as a small (circa 80-person) software outsourcing company until its eventual demise in 2002.

\subsection{Nco, a Jamaican Nearshore Enterprise}

Nco was established in 1995 by an Indian expatriate living in the USA, in collaboration with a US entrepreneur to provide a "near shore alternative to offshore programming" in the Caribbean. Officials from a Jamaican government agency, the Montego Bay Free Zone, aware of Nco's interest, approached the entrepreneurs with the possibility of making that investment in Jamaica. The island was eventually chosen because in addition to its proximity, it possessed a cheap, educated workforce of native English speakers and a functional telecommunications infrastructure. Having researched the problems encountered by the Barbados nearshore operation, the founders decided on a different strategy for Nco: "... we felt that the way to build [the company] would be to establish a training program, develop our own workforce and then use them..." (CEO, Nco)

A training school, the Caribbean Software Institute (CSI), was therefore established in collaboration with the government of Jamaica and Jamaican, US and UK academic institutions. The curriculum was developed by the academic partners and was closely tied to Nco's needs, focusing on the latest technological areas, such as web and Java programming. 
Applicants to the program were to possess at least a high-school education, but beyond that no computer literacy was mandated. The ten-month course was expected to bring the complete novice up to the standard of computer programmer. An "incubation" process, where the graduate would be given on-the-job training at a software development company, would then be initiated. Nco agreed to limit foreign recruitment to what was deemed necessary to staff the "incubator". The depressed economy of Jamaica, that severely limited the opportunities available for educated Jamaicans in their chosen fields, enhanced the attractiveness of this approach. Nco hired all the graduates of the first year and a significant percentage of the second group.

The collaboration has endured despite the complexity of the relationships among the partners. Interviewees attributed this to their level of commitment, both the government's involvement in sponsoring and funding the project, and Nco's follow-through in hiring the trained programmers. Other contributing factors were the presence of senior representatives of the partnership on the managing board of the CSI and the chairmanship of that board by the government training agency. One aspect that seemed to help was a common vision shared by the public and private partners that this project gave "the opportunity for an industry to develop to help [the Jamaican] economy", a view embraced by a government pursuing the path towards diversification of the economy by "get[ting] our brighter Jamaicans to upscale into programming". The need to develop the skills base of local Jamaicans through involvement in local projects was also seen to be important.

Nco aimed to have a diverse spread of clients to help build their capability and thus increase confidence in the nearshore idea. They initiated 'partnering' schemes with at least two of their customers, who pledged to help sell the 'nearshore' option. The company also had contracts and partnering arrangements with Caribbean and Jamaican ventures, including Jamaican government agencies, demonstrating the level of trust that had been achieved in the collaboration. Another strategy employed by the company was to get a foothold in the local market to use as a springboard for exporting services, taking advantage, for example, of egovernment work sponsored by international aid agencies to grow their local talent.

Nco's Jamaican location appeared to provide some of the expected advantages. For example, proximity was seen as improving communication, collaboration and control and the company executives were able to manage the venture from their base in the USA, needing only a few visits per year to the island. In addition, aspects of the Jamaican culture, such as English being the main language were felt to be helpful, while it was considered that potential customers identified favourably with the familiar Jamaican environment:

"You can leave Atlanta, Georgia, Charlotte, North Carolina and be [in Jamaica] in 2.5 hours and you're on the same time zone and you can stay in a Holiday Inn, you can stay in a Ritz Carlton, you can stay in named hotels with good venues while you're doing your business in Jamaica" (Chairman, Nco).

Notwithstanding the island's inherent locational advantages, the nearshore entrepreneurs did experience issues in convincing customers to send software work there:

“... and one of Nco's difficulties in attracting clients and business, has been that the image of the Caribbean certainly does not suggest high tech solutions to your business problems... and Jamaica has a very laid-back and "no problem, Mon" image in the USA" (Member of Board, Furman University). 
The company employed several strategies to overcome this problem. Customers were invited to come to the island to witness the facilities first hand and interact with the staff, something that was facilitated by the island's proximity and congeniality. Nco sourced its outwardfacing staff from the USA, people with experience in well-known US corporations, but still linked somehow to the local context. For example, Nco's most senior resident staff member was an expatriate Indian with experience in a US-based firm and previous knowledge of living and working in Jamaica. The CSI also employed the strategy of hiring foreign expertise in the first instance to be replaced eventually by Jamaican staff. It was felt that a certain standard should be kept that would be internationally recognised. The local faculty, when interviewed, felt that they were contributing to the community through bringing in expertise gathered from abroad.

At times, Nco's policies towards attaining "international" recognition seemed to contradict the stated intention of assimilating into the local environment. For example, they adopted North American business practices such as non-surveillance of staff, overtime work shared by both managers and staff to meet deadlines, arrangements for staff to stay overnight on-site and flexible working hours. At times, also, for the local organisations interacting with Nco, their image was a distinctly "foreign" one.

At the time of the study, numbers of staff had risen from an initial 15 to close to 100,83 of whom were CSI graduates. The majority of the staff were Jamaican, in technical as well as administrative positions, with expatriate Indians making up only about $10 \%$ of the total workforce, although most of these were in senior positions. The venture continues to thrive and has achieved SEI CMM Level 4 competence in software engineering (Zagada Institute, 2004) and has partnerships with leading US and Caribbean companies, specialising in products related to tourism and the hospitality industry.

\section{Case Analyses}

Analysis of the characteristics of location that appeared to have influenced the performance of the two nearshore ventures suggested that these could be grouped under five headings, namely, physical, economic, resource-based, government-role related, and cultural. Physical features were those related to geographical aspects of the location. Fiscal policies, GDP and other aspects related to trade and industry were called economic features. The availability of human, capital and infrastructural resources was grouped under the heading of resource-based features. Government-role related aspects pertained to those policies or actions carried out by the local government. Cultural features pertained to business practices, language and social and historical traditions.

These characteristics could be further classified in terms of whether they were espoused, unanticipated or remediable. The espoused characteristics comprised those that the firms explicitly identified as having been factors in their choice of location; unanticipated characteristics were those that proved to be significant, although they were not initially perceived to be relevant to the location decision; and remediable characteristics were those undesirable aspects of a location that the firms were able to overcome, or turn to their advantage.

\section{1. $\quad$ Espoused Characteristics}

In terms of physical features, a primary motivation for both firms in choosing Caribbean locations was to take advantage of the convenience of travel and similarity in time zones that 
the proximity of these islands afforded. Both firms appeared to benefit from this closeness through quicker, timelier access to and from the USA and better remote management of communication, coordination and control issues.

Economics is a key driver of offshoring in general, and cost was, not surprisingly, a critical factor in both firms' choice of location. It was assumed that by setting up development centres in countries with per capita incomes considerably lower than those in the USA, they could attract well-qualified employees at wage rates that, while higher than those in the limited alternative occupations on the islands, would enable the firms to be highly competitive with onshore production and comparable to offshore production, but without the latter's perceived disadvantages.

With regard to resources, the importance of a well educated local workforce was also recognised especially by Nco. The existence of well-established secondary and tertiary education systems on the islands, based, due to their colonial history, on a well-recognised British model, was therefore seen as desirable, even if not, in ZCO's case, essential. That the state of the local economy, particularly in Jamaica, meant that there was substantial underutilisation of this educated workforce, moreover, further enhanced the competitiveness of the firms' wage costs and their ability to select the best employees. The quality of the infrastructure in terms of the telecommunications system and the easily accessible international airports in Barbados and Montego Bay also figured significantly in the decision to choose these locations.

The government played a pivotal role in providing a facilitating political environment. Thus Barbados' reputation for political stability made it particularly attractive for ZCO. Also supportive were the governments' very favourable investment terms of the International Business Company (IBC) incentives in Barbados and the tax free allowances and investment park privileges of the Free Zone. Concessions such as these were helpful in enabling the firms' initial start-up. Additionally, favourable government policies, for example, on work permits for ZCOB or providing government-sponsored higher education training for Nco, were useful in assisting these enterprises with their specific models of nearshore implementation.

The islands also exhibited some culturally compatible features such as familiarity with American culture and use of English, especially in a region of predominantly Spanishspeaking countries. This familiarity with American business culture also helped to differentiate the nearshore companies from the contrasting, reportedly culturally-foreign, Indian alternatives.

\subsection{Unanticipated Characteristics}

It was found that many locational features were unanticipated by the nearshore vendors. For instance, the attraction of Barbados and Montego Bay, as major tourist destinations, which did not significantly influence the initial decisions to set up there, emerged as a source of unexpected benefit in practice. In the case of $\mathrm{ZCO}$, it helped to make the location attractive to programmers and business people alike. Nco's executives reported similar success in attracting clients to visit Montego Bay because of its familiar setting with recognised hotels.

The contribution of the islands' status as former British colonies to the educational standard of the workforce has already been identified, but this heritage also influenced perceptions of 
the islands' political and economic stability and the quality of the telecommunications infrastructure, which had been installed by a British telecommunications company that had been operating in the region for over 100 years. The existence of these linkages created some degree of legitimacy and reassurance for the entrepreneurs and provided a basis on which to build client relationships.

The islands' economic and political weakness, that gave an advantage to international investors such as the nearshore entrepreneurs, may also be attributed to their colonial legacy. In the ZCOB case, this enabled them to establish a "company town" with few linkages to the local community while Nco adopted American management styles and externally-oriented training objectives at CSI.

Finally, the existence of government policies that were complementary to the nearshore vendors such as alignment with the island governments' objectives toward expanding the information technology sector, worked to the two firms' benefit. This was most noticeable in the Nco case, with the proactive role of the Jamaican government in approaching the entrepreneurs, the commitment of government-led bodies' support for CSI and their sustained resource and financial commitments. Nco also benefited from local software projects funded by international development aid.

\subsection{Remediable Characteristics}

Notwithstanding the advantageous, if unanticipated, characteristics discussed above, some issues still needed to be resolved. The touristic allure of the islands, for example, reduced their credibility as sites for software development. ZCOB sought to overcome this perception by creating its "programmer's paradise" with imported Indian staff and thereby gaining reputation by association with the well-recognised Indian offshore industry. The weakness of this approach was revealed, however, by the expatriates' use of ZCOB as a stepping stone to the USA, rather than feeling any ties to their new location. These constructed associations similarly failed to hold for ZCOB's clients whose loyalty to the concept did not match that of the "well understood" Indian model.

Nco, on the other hand, tackled the image issue by cultivating a US-based outward-facing interface with clients, training local staff in US business etiquette, and promoting US-inspired management techniques, which differentiated them from other "Jamaican-run" companies (as could be easily demonstrated to clients, thanks to the accessible location). At the same time, they also attempted to develop local expertise on local projects so as to build confidence in the Jamaicans' abilities.

The lack of suitably trained human resources and a significant local software market was similarly addressed in different ways by the two companies. ZCOB developed an exportoriented and externally dependent approach. This made them vulnerable, however, to changes in external market demand as they lacked a local client base (further exacerbating the problem of staff retention).

Nco's approach to this issue was to develop local expertise and create linkages to the local market, for example through the initial "incubation" of local employees by highly-skilled, imported technical staff. Additionally, Nco's "partnering" schemes with government and local agencies helped ensure political commitment to the project and ongoing local work relevant to, and embedded in, the Jamaican context. A summary of the locational 
characteristics and features influencing the viability of the nearshore ventures is given in Table 2.

Table 2. Characteristics affecting the suitability of a location for nearshore software outsourcing

\begin{tabular}{|c|c|c|c|}
\hline Characteristic & Espoused & Unanticipated & Remediable \\
\hline Physical & $\begin{array}{ll}\text { - } & \text { Proximity } \\
\text { - } & \text { Similar time zones } \\
\text { - } & \text { Accessibility } \\
\end{array}$ & $\begin{array}{ll}\text { - } & \text { Attractive } \\
\text { environment }\end{array}$ & \\
\hline Economic & - Lower wages & $\begin{array}{l}\text { Weak economic } \\
\& \text { political } \\
\text { position of host } \\
\text { country }\end{array}$ & $\begin{array}{l}\text { Lack of local } \\
\text { software market }\end{array}$ \\
\hline $\begin{array}{l}\text { Resource- } \\
\text { based }\end{array}$ & $\begin{array}{ll}\text { - } & \text { Telecommunications } \\
\text { infrastructure } \\
\text { - } \\
\text { International airports } \\
\end{array}$ & & $\begin{array}{l}\text { - Lack of local } \\
\text { skills }\end{array}$ \\
\hline $\begin{array}{l}\text { Government } \\
\text { role }\end{array}$ & $\begin{array}{ll}\text { - } & \text { Investment friendly } \\
\text { - } & \text { Political \& economic } \\
& \text { stability } \\
\text { - } & \text { Favourable policies }\end{array}$ & $\begin{array}{ll}\text { - } & \text { Active } \\
\text { commitment } \\
\text { - } \\
\text { Cooperation and } \\
\text { facilitation }\end{array}$ & \\
\hline Cultural & $\begin{array}{l}\text { Familiarity with } \\
\text { American business } \\
\text { environment } \\
\text { - Shared language }\end{array}$ & 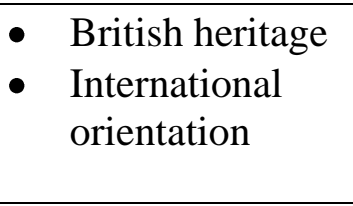 & $\begin{array}{l}\text { Unfavourable } \\
\text { cultural } \\
\text { associations }\end{array}$ \\
\hline
\end{tabular}

\section{Discussion}

From the case analyses above, it can be inferred that both companies relied, to some extent, on a "placeless logic" (Sahay et al. 2003, p. 35) in choosing and establishing their nearshore sites. Thus the characteristics identified (espoused) by the companies as having played a major role in their choice of location were primarily focused on generic features that were seen, on the basis of concepts such as location substitutability (Cox 1997a), to be necessary and sufficient conditions for a viable offshore venture. This was most clearly illustrated in ZCOB's strategy for nearshore software development, which gave little consideration to the specific characteristics of their chosen location. Moreover, as such characteristics were assumed to be a given for any location, little attention was paid to whether anything could be done to remedy any perceived weaknesses

Similarly, notwithstanding Nco's greater attention to place, especially with respect to the development of local skills and markets, their strategy was the product of two entrepreneurs seeking a cheap and convenient location for their venture, with no particular allegiance to Jamaica over any other. That the initiative of the Jamaican officials alerted them to its suitability and that Nco subsequently sought to develop close links with the locale, came after the fact of the entrepreneurs' adoption of assumptions of placelessness that rendered the idea of nearshore development conceivable in the first place. Had they not believed that it would be possible to set up a software development centre in the Caribbean, a region with little track-record in the field, then they would not have considered a site there in the first place. 
Had they not had their international connections and experience it might have been considerably harder for them to set up the initiative.

As the cases also illustrated, however, the pursuit of placelessness does not mean that ventures can ignore the influence of location. ZCOB's "enclave" approach (Heeks 1999) still had social, economic and political effects on Barbados, that had repercussions for the company such as increased local costs with negligible effect on local employment. The lack of engagement with the local community and economy were also seen to have contributed to ZCOB's later difficulties.

It was not just the more obvious characteristics of a location that affected its suitability, but also various intangible ones. Thus English language was recognised to be desirable, but a level of cultural compatibility and awareness also proved to be important. Although this was an advantage in terms of attracting clients, it applied negatively in ZCOB's case, in terms of the lack of identification of the expatriate staff with their new location, perhaps exacerbated by the company's promotion of the placeless "programmers' paradise" concept.

The lack of attention to specific local characteristics also meant that ZCOB failed to exploit endemic features of its chosen location or to identify potentially advantageous features of alternative locations. Thus practitioners suggested that ZCOB might have done better to have focused on certain types of software projects that might be better suited to features associated with the Caribbean locale, such as the ability to visit frequently from the USA, the existing technical capabilities of the available workforce or the opportunity of specialising in some niche area unique to the Caribbean experience (cf. late entrant strategies in Heeks et al. 2004).

This predominantly placeless approach also resulted in passive involvement by the Barbados government. Indeed, their generous incentives reduced the economic benefits that the country might have gained from the venture, illustrating the relationship between placelessness and powerlessness (Castells 1996).

Nco's strategy was generally more differentiated and integrated with local conditions, as the strategies of "incubation" and "partnering" attest. The positive results of this were demonstrated in many ways, including: active government support and commitment (financially and politically); demonstrable "upskilling" of economically disadvantaged workers; sustainable impact on the economy through encouraging new investment and providing employment; and contribution to economic development of the country through involvement in international development projects.

The cases also illustrated that characteristics of location may be highly specific, suggesting that assessments of opportunities at a regional, or even national, level may be potentially misleading. Thus the islands in the Caribbean, despite some commonalities, each offer distinctive characteristics, such as Trinidad's significant Indian population, and even within Jamaica, the characteristics of the Montego Bay Free Zone differ from the rest of the Island. Consideration of location characteristics therefore needs to be made at a high level of detail.

Finally, the cases may be seen to show that some characteristics of a location are open to change. In one sense this is what the placeless logic suggests - with enough money any locational disadvantage can be overcome. What this does not perhaps account for is that, in a risky and cost-driven industry, such investments lower competitiveness and reduce the 
chances that investments will be repaid. Nco's more cautious and collaborative strategy of working to improve local resources seemed to be more sustainable.

\section{Conclusions}

Nearshore software outsourcing, and offshoring more generally, may be seen as manifestations of the contribution of ICTs to globalisation. Without business networks operating on a global scale and their supporting ICT infrastructures, offshoring would not be possible (or perhaps even conceivable). An influential theme in discussions of globalisation has been the idea that ICTs have rendered the location of work irrelevant.

The cases presented in this paper have shown the power of these ideas in shaping the strategies of nearshore software development companies, but also their limitations. The concept of establishing software development centres in the Caribbean relies upon the notion that the absence of an existing software industry need be no barrier to setting up a development centre in a country and one of the case study companies sought to do this in a way that was largely independent of its specific location.

Notwithstanding the association of offshoring with placelessness, however, the nearshore evidence suggests that a number of location-specific characteristics may have had an important influence on the viability of these ventures. These include aspects relating to the physical, economic and cultural setting, local resources and government policy. Some of these are widely-recognised, and indeed are identified as selection criteria for location decisions, even for companies adopting a "placeless logic". Others, however, emerged as significant in the experience of the case study companies. The cases also suggest that companies can be active in shaping some of these characteristics to their advantage, rather than treating them as given.

Companies considering establishing nearshore, and maybe also offshore, development centres and clients engaging with such vendors, therefore need to treat notions of placelessness with caution. While they are an essential component of the case for offshoring, this does not make location irrelevant. Rather it is in the interplay of disembedded and embedded practices that strategies for nearshoring need to be made.

Thus, for vendors considering setting up nearshore, and perhaps offshore, development centres in non-traditional locations the findings suggest that they need to recognise both the placeless character of such work, and also the continuing significance of location. For example, sites are likely to need not only the basic infrastructure and physical characteristics but also facilitating cultural and socio-political environments if they are to succeed. Some of these characteristics, moreover, may be highly localised, suggesting that opportunities may be quite place-specific. Vendors therefore need to develop ways of evaluating these more intangible and localised characteristics so as to determine viability of a particular model succeeding in the chosen environment. This would seem likely to require either personal familiarity with specific locations through visits (which would also serve to illustrate the convenience, or otherwise, of the site) or, at least, interaction with those with relevant experience.

For client companies considering outsourcing development work to nearshore locations, the decision needs to address the long-term sustainability of doing business with a vendor in the particular environment. For locations that are not well known or established, clients would 
need to develop some familiarity with the resources there through a similar process to that suggested for vendors. The case findings suggest that, notwithstanding the logic of placelessness, the level of a venture's engagement with its local setting, the greater may be its sustainability. There may also be opportunities for clients to be more active in contributing to the viability of a nearshore partnership through the commissioning of projects that exploit the particular characteristics of the nearshore locale, or by promoting the concept to build wider recognition.

While the two case studies provide some insight on the, as yet, under-researched field of nearshore software outsourcing, they do not claim to be representative of practices in this area. The findings must therefore be considered provisional. Nevertheless, they indicate that there may be significant opportunities for further studies to explore the complex interplay of ideas of placelessness and the specifics of location involved in nearshore, and perhaps also offshore, outsourcing as it develops in the context of globalisation.

\section{References}

Abbott, P.Y., and Jones, M.R. "The importance of being nearest: nearshore software outsourcing and globalisation discourse," in: IFIP TC8/WG 8.2 Working Conference on Global and Organizational Discourse about Information Technology, E.A. Wynn, E.A. Whitley, M.D. Myers and J.I. DeGross (eds.), Kluwer Academic Publishers, Barcelona, Spain, 2002, pp. 375-397.

Agar, M.H. The Professional Stranger: An Informal Introduction to Ethnography Academic Press Inc., New York, NY, 1980.

Appadurai, A. Modernity at Large: Cultural Dimensions of Globalization University of Minnesota Press, Minneapolis, Minnesota, 1996.

Cairncross, F. The Death of Distance: How the Communications Revolution Will Change Our Lives Orion Publishing, London, 1997.

Carmel, E. Global Software Teams: Collaborating Across Borders and Time Zones Prentice Hall, Upper Saddle River, New Jersey, 1999.

Carmel, E. "The new software exporting nations: success factors," Electronic Journal of Information Systems in Developing Countries (13:4) 2003, pp 1-12.

Carmel, E., and Abbott, P. "Why nearshore means that distance matters," Communications of the ACM Forthcoming.

Carmel, E., and Agarwal, R. "Tactical approaches for alleviating distance in global software development," IEEE Software (18:2) 2001, pp 22-29.

Castells, M. The Rise of the Network Society Oxford University Press, Oxford, 1996.

Corbin, J., and Strauss, A. "Grounded theory research: procedures, canons, and evaluative criteria," Qualitative Sociology (13:1) 1990, pp 3-21. 
Cox, K.R. "Introduction: globalization and its politics in question," in: Spaces of Globalization: Reasserting the Power of the Local, K.R. Cox (ed.), Guilford Press, New York, 1997a, pp. 1-18.

Cox, K.R. Spaces of Globalization: Reasserting the Power of the Local Guilford Press, New York, 1997b.

Economist "The rise of nearshoring," in: Economist, 2005, pp. 65-67.

Edwards, J. "The farthest shore," CFO.com, 2004.

Express "Nearshore: India Software Inc moves closer for comfort," Express Computer Online, 2004.

Friedman, T. The World is Flat: A Brief History of the Twenty-First Century Allen Lane, London, 2005.

Giddens, A. Consequences of Modernity Polity Press, Cambridge, 1990.

Goddard, J., and Richardson, R. "Why geography will still matter: what jobs go where?" in: Information and Communication Technologies: Visions and Realities, W.H. Dutton (ed.), Oxford University Press, Oxford, 1996, pp. 197-214.

Heeks, R., and Nicholson, B. "Software Export Success Factors and Strategies in 'Follower' Nations," Competition \& Change (8:3) 2004, pp 267-303.

Heeks, R.B. "Software strategies in developing countries," Communications of the ACM ( 42:6) 1999, pp 15-20.

King, J. "Sun and Pay Lure Coders to Barbados Outsourcer," in: Computerworld, 1999, p. 24.

Krishna, S., Ojha, A.K., and Barrett, M. "Competitive advantage in the software industry: an analysis of the Indian experience," in: Information Technology in Context, C. Avgerou and G. Walsham (eds.), Ashgate, Aldershot, 2000, pp. 182-197.

Minevich, M., and Richter, F. "The Global Outsourcing Report: opportunities, costs and risks," Going Global Ventures Inc., HORASIS.

Ohmae, K. The Borderless World: Power and Strategy in the Global Marketplace HarperCollins, London, 1990.

Orlikowski, W.J., and Baroudi, J.J. "Studying information technology in organizations: research approaches and assumptions," Information Systems Research (2:1) 1991, pp $1-28$.

Quah, D.T. "A weightless economy," UNESCO Courier (51:12) 1998, pp 18-20.

Radkevitch, U. "Belarus Attempts to Become the Eastern European Bangalore," Outsourcing Journal, Everest Group, 2005.

Rao, M.T. "Key issues for global IT sourcing: country and individual factors," Information Systems Management (21:3), Summer 2004 2004, pp 16-21. 
Robertson, R. Globalization: Social Theory and Global Culture Sage, London, 1992.

Sahay, S., Nicholson, B., and Krishna, S. Global IT Outsourcing: Software Development Across Borders Cambridge University Press, Cambridge, 2003.

Sarker, S., and Sahay, S. "Implications of space and time for distributed work: an interpretive study of US-Norwegian systems development teams," European Journal of Information Systems (13:1) 2004, pp 3-20.

Satyam "Satyam extends its global reach with a New Development Centre in Hungary," Satyam Computer Services Ltd., 2004.

Storper, M. "Territories, flows, and hierarchies in the global economy," in: Spaces of Globalization: Reasserting the Power of the Local, K.R. Cox (ed.), Guilford Press, New York, 1997, pp. 19-44.

Tran, M. "From Bangalore to Bucharest," in: The Guardian Unlimited, 2004.

Walsham, G. Interpreting Information Systems in Organizations Wiley \& Sons, Chichester, 1993.

Zatolyuk, S., and Allgood, B. "Evaluating a country for offshore outsourcing: software development providers in the Ukraine," Information Systems Management (21:3) 2004, pp 28-33. 